2017 , volume 6 , issue 4

Jaworski, P., Liberadzki, K., \& Liberadzki, M. (2017). Contagion and divergence on sovereign bond markets. Copernican Journal of Finance \& Accounting, 6(4), 39-68. http://dx.doi.org/10.12775/ CJFA.2017.022

\author{
PIOTR JAWORSKI ${ }^{*}$ \\ University of Warsaw \\ KamIL LIBERADZKI ${ }^{* *}$ \\ Warsaw School of Economics \\ MarCin LiberadzKI ${ }^{* * *}$ \\ Warsaw School of Economics

\section{CONTAGION AND DIVERGENCE ON SOVEREIGN BOND MARKETS}

Keywords: sovereign credit risk, global debt market, contagion effect, divergence effect, stochastic modeling, copulas.

J E L Classification: C, C5, G, G1, G15.

Abstract: The paper gives evidence for significant interdependency between sovereign bond yields during pre-crisis period as well as after the recent global debt crisis broke out. These interdependencies can be classified either as contagion or divergence. Both effects should be understood as an increase in interdependency among different assets

Date of submission: March 2, 2018; date of acceptance: April 10, 2018.

* Contact information: p.jaworski@mimuw.edu.pl, Institute of Mathematics, University of Warsaw, Banacha 2, 02-097 Warszawa, Poland, phone: +48 225544523.

** Contact information: corresponding author, kliber@sgh.waw.pl, Institute of Finance, Warsaw School of Economics, Madalińskiego 6/8, 02-513 Warszawa, Poland, phone: +48225649320.

*** Contact information: mliber@sgh.waw.pl, Institute of Finance, Warsaw School of Economics, Madalińskiego 6/8, 02-513 Warszawa, Poland, phone: +48 2256493 20; ORCID ID: https://orcid.org/0000-0001-8236-004X.

The authors are very grateful for the financial support from Polish National Science Center programme No 2015/17/B/HS4/00911. 
as a result of a significant shock. Contagion refers to positive interdependency, while the negative correlation illustrates divergence effect. Basing on selected bonds, we found out that divergence effect prevails over contagion. What is more, there has been more divergence among the European Monetary Union (EMU) countries than between the EMU sovereigns and Japanese or the US bonds. Despite the increase of contagion level after the crisis, there was no worldwide retreat from bond markets as a result of global turbulences. While there is a numerous literature on sovereign bond contagion, we propose our methodology for bond divergence effect measuring. The paper organizes and presents main concepts for contagion effect modeling within both spatial and time approach. As the same index is utilized for contagion and divergence modeling, it is possible to analyze and compare these two opposite effects together basing on selected sovereign bond market data.

\section{IIITRODUCTION}

\section{Overview}

Portfolio selection has developed the methods of limiting the total portfolio risk by means of diversification. The occurrence of contagion effect devastated that approach since financial crises have underlined that the markets tend to become more dependent during crises than they are during calmer periods. Not taking this effect, called 'contagion' into consideration, may lead to significant underestimation of portfolio risk in case of extreme value changes of different instruments included. Understanding the idea of contagion provides useful benefits when dealing with financial risk. For instance, diversification strategies for building portfolios may fail under contagion, i.e., when there is a shift in the dependence among assets in crisis period (Durante, Foscolo, Jaworski \& Wang, 2014, p. 4023). Bradley and Taqqu (2004, p. 8) suggested to focus on probability distribution functions of target financial time series and, in particular, at the discrepancies between the probability mass concentrated in tail and central sets of these distributions. What is also new in our article is that we formulate the notion of 'divergence' effect that states in opposition to 'comovement' effect (which we explain in detail further in the text).

The new approach to portfolio risk management (Durante \& Jaworski, 2010, p. 551) applied in this article is innovative in the way that instead of using Person correlation coefficient we rely on information based on copula-class functions that fully describe the interdependence between returns on different assets considered in a portfolio. This of interdependency evaluation will be used for analyzing the selected sovereign bond yields data 
in the pre-crises and post-crises periods. The practical importance of the research and our findings is that it may lead to improving of calculation of sovereign bond portfolio risk. As we refer strictly to portfolio theory, we do not carry out fundamental analysis of bond issuers. Selecting the sample based on heuristic analysis, we conduct statistical evaluation of actual interdependencies between the instruments. Initially we tried to heuristically pre-select the bond sample including the issuers that might be categorized into: "safe haven countries" (Germany, US, Australia), "emerging markets" (Poland) and "troubled economies" (Portugal, Italy) and Japan (not categorized). We restrict ourselves from investigating the fundamental reasons for observed price behavior, we rather follow the stress-testing approach and answer the question: what happens with the yields of different sovereign bonds when there is a turmoil on the global market, not inquiring for the fundamental reasons.

The importance and practical value for this research may be confirmed by what happened during the recent financial crisis, which broke out in the US and spread globally, resulted in series of shocks across the markets. The last couple of years have seen the transformation of the global financial crisis into a sovereign debt crisis. Sovereign bond markets have become increasingly integrated both domestically and internationally long before year 2008. The nature of these interdependencies and the shock transmission channels are still not well understood. Interdependency may be translated either into contagion or divergence effect. The thesis of our paper is, that there is a significant interdependency between sovereign bond prices both during tranquil and contraction periods. This interdependency includes both contagion and divergence whereas at turbulent times contagion tends to increase while divergence remains still at significant level.

The further goal of our research is to quantify contagion effect and divergence effect referring to selected sovereign bond data before and after the outbreak of the recent global crisis. Therefore we propose the construction of proper contagion and divergence index with respect to bond yields or prices.

The European government bond market integration was one of the positive results of the European Monetary Union from its advent till late 2008. However, it has been found out at that time that the global shocks affect Germany and the rest of euro bond markets in various levels (Balli, 2009, p. 331). The literature has responded to the EMU crisis through a series of 
empirical studies. It has been observed during global contraction, that the global risk perception with investment in sovereign bonds relative to safe havens of US and Germany increases. When it comes to the EMU countries, there is fundamental explanation for this: eliminating the exchange rate parity, no adjustment mechanism was retained to correct fundamental divergence (Mazier \& Petit, 2013, p. 513). To stir things up, the EMU countries were slow even to track rising divergences (Muellbauer, 2013, p. 610). As a result, German government bonds operated as a flight-to- quality asset, a feature apparent in figure 2. Ehrmann, Fratzscher and Rigobon (2005) analyze the degree of financial transmission between money, bond and equity markets and exchange rates within and between the United States andthe euro area. They find that asset prices react strongest to other domestic asset price shocks, andthat there are also substantial international spillovers, both within and across asset classes. Theresults underline the dominance of US markets as the main driver of global financial markets: US financial markets explain, on average, more than $25 \%$ of movements in euro area financial markets, whereas euro area markets account only for about $8 \%$ of US asset price changes.

Arghyrou and Kontonikas (2012, p. 658) present the concept ofcrisis transmission through the two channels (periphery-to-core and periphery-to-periphery transmission): increasing core-periphery divergence signals an increased probability of aggregating fiscal risks at the EU-level and may increase future borrowing requirements from the core group to cover the potential support efforts. Hence, increasing divergence may finally cause contagion from the peripherygroup to the core group.

Mink and de Haan (2013, p. 102) discover contagion between Greece and indebted peripheral EMU countries (Portugal, Ireland, Spain) as a result of the fiscal crisis. Antonakakis and Vergos (2013, p. 258) give examples of empirical studies showing convergence of spreads in EMU countries before the 2007 and subsequent divergence of bond yields in countries with weaker fundamentals.

Our contribution is that we focus equally on sovereign bond contagion as well as on divergence as we find the latter effect (divergence) being somehow overlooked in the literature. Therefore we propose a nonlinear contagion and divergence index enabling direct comparison of these two effects. What is more, working on bond yields rather than prices, we analyze the yields on each yield curve short end, its middle part and long seg- 
ment. Therefore it is possible to observe the yield curve behavior as a result of shocks and contagion/divergence effects between bonds of different maturities.

There is a broad array of techniques applied for quantifying contagion effect, thus the paper somehow organizes these models inspired first and foremost by approach of Durante and Jaworski (2010, p. 551) and Jaworski and Pitera (2014, p. 303). Furthermore, the paper examines how these techniques may also be used for modeling bond yield divergence effect.

\section{Market contagion definitions}

Contagion is defined commonly in the literature as the change in the way countries own fundamentals or other factors are priced during a crisis period, i.e. a change in the reaction of financial markets either in response to observable factors, such as changes in sovereign risk among neighboring countries, or due to unobservable ones such as herding behavior of market participants (Beirne \& Fratzscher, 2013, p. 60). The World Bank (2016) makes use of following definitions:

- Broad definition: Financial contagion is usually referred to as a cross-market transmission of shocks or the general cross-market spillover effects. It can take place both during good times and bad times. Thus, contagion does not need to be related to crises. However, it is emphasized during crisis times. If present, it may mitigate the benefits of diversification precisely when those benefits are needed most and have serious consequences for investors. Therefore, understanding this highly nonlinear effect is of great interest not only to financial theorists but to practitioners as well (Jaworski \& Pitera, 2014, p. 303; Durante \& Jaworski, 2010, p. 555).

- Restrictive Definition: Contagion is the transmission of shocks to other countries or the cross-country correlation, beyond any fundamental link among the countries and beyond common shocks. This definition is usually referred as excess co-movement, commonly explained by herding behavior. The World Bank recognizes following categories of fundamental links: financial links, real links and political links.

- Very Restrictive Definition: Contagion occurs when cross-country correlations increase during "crisis times" relative to correlations during "tranquil times". 
According to its probabilistic definition contagion is a significant growth of probability of shock in one country (default of a company respectively) on condition that shock occurs in other country (other company defaults respectively).

Contagion process can be translated into three effects: 1) spillover, 2) transmission, 3) co-movement. To avoid confusions, we propose the following description of these above-mentioned effects:

Spillover: the contagion spreads as a jump process. Beyond a threshold the changes become leap like (often deferred) usually strengthened by common level of investors stop loss orders.

Transmission: the spread occurs continuously. The market participants levels of stop loss orders are usually dispersed. Positions are closed at different time.

Co-movement: the changes occur simultaneously (with no time delay). The same effect however would be classified as spillover if data is measured frequently or co-movement if data is gathered at more time intervals.

There is however much disagreement among economists about what contagion is and how it should be tested for empirically. Mink and de Haan (2013, p. 102) refer to following definition: contagion is an episode in which there are significant immediate effects in a number of countries following an event that is, when the consequences are fast and furious and evolve over a matter of hours or days. When the effect of the event is gradual, they refer to this as spillovers rather than contagion. Also in other cases one may question whether the label of contagion is adequate. For instance, in a widely used approach, contagion is inferred by a significant rise in the correlation of asset returns in crisis periods compared to tranquil periods (Mink \& de Haan, 2013, p. 102).

Basically, these studies examine whether cross correlations between markets increase significantly during a major crisis (crisis period) or after a crisis (post-crisis period) in comparison to periods before the crisis (pre-crisis period). If the correlations increased significantly during and after crisis periods, in comparison to pre-crisis periods, the authors conclude evidence in favor of contagion (Yunus, 2013, p. 327). 


\section{THE RESEARCH METHODOLOGY AND THE COURSE OF THE RESEARCH PROCESS}

\section{The framework for market contagion modeling}

Figure 1. Central (on the right, around v1) and extreme values (on the left, around v2)

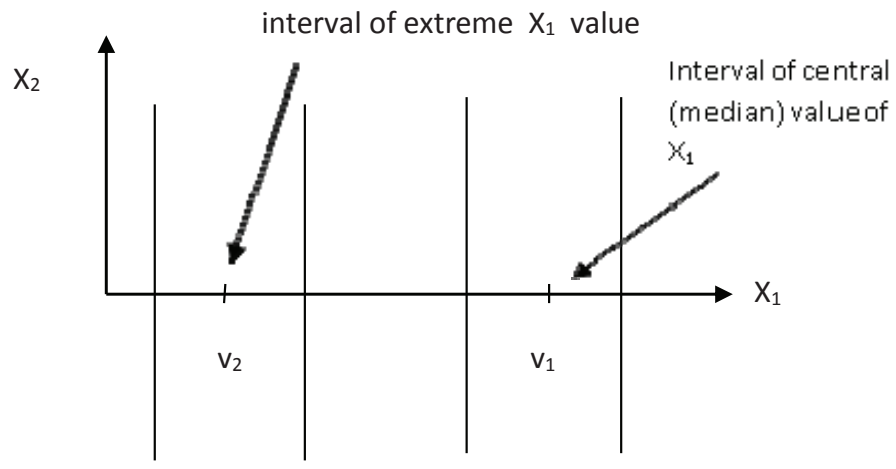

S o u r c e : own calculations.

Co-movements, the main objective of our study, may be approximated by static models like copula class models. Modeling contagion may refer either to spatial analysis approach or time analysis approach.

Within the spatial approach, the random variable changes grouped into moderate and significant ones. In the spatial framework, according to Bradley and Taqqu (2004, p. 9), "there is contagion from market $X 1$ to market $X_{2}$ if there is more dependence between $\mathrm{X}_{1}$ and $\mathrm{X}_{2}$ when $\mathrm{X}_{1}$ is doing badly than when $\mathrm{X}_{1}$ exhibits typical performance".

Let us consider $X_{t}$ to be a two-dimensional stochastic process. Assume the $X_{t}$ is stationary and ergodic. If $m(t)$ is a type I regression function:

$$
m(v)=E\left(X_{t, 2} \mid X_{t, 1}=v\right) .
$$

There is a linear contagion effect referring to intervals $[a, b]$ and $[c, d]$, $-\infty \leq a<b \leq c<d \leq+\infty$, when: 


$$
P\left(X_{t, 1} \in[a, b]\right)>0<P\left(X_{t, 1} \in[c, d]\right) \quad \text { and } \quad \frac{m(b)-m(a)}{b-a}>\frac{m(d)-m(c)}{d-c} .
$$

In case of normal joint probability distribution of $\mathrm{X}_{\mathrm{t}^{\prime}}$, both the type I and type II regressions are linear:

$$
m(v)=\alpha+\beta v, \quad \beta=\operatorname{Cov}\left(X_{t, 1}, X_{t, 2}\right) / D^{2}\left(X_{1}\right), \quad \alpha=E\left(X_{t, 2}-\beta E\left(X_{t, 1}\right)\right) .
$$

Since the $m^{\prime}(v)=\beta$ is constant, there is no contagion effect unless we go beyond the normal distribution assumption. Bradley and Taqqu (2004, p. 9) point out that if the first derivative is equal $\beta$, the contagion exists only if $\beta$ increases for extreme value interval (figure 1).

Coefficient $\beta$ should be calculated separately for each 'stripe' around the value $v_{i}$ (as presented on the figure 1). Maintaining the assumption on $m(v)$ linearity within each value interval, it is recommended to use the difference quotient instead of the first derivative.

Another approach within the spatial framework utilizes copula theory. The term 'copula' was coined by Sklar (1959, p. 229), who proved that a collection of marginal distributions may be merged together by using copula transformation to form a model of multivariate distribution. Any joint distribution $\mathrm{F}$ of a set of random variables $X_{1}, X_{2}, \mathrm{~K}, X_{n}$ can be separated into two parts: the first is the combination of the marginals that (if expressed in cumulative distribution form) are $F_{1}(\cdot)$ where $F_{i}(x)=P\left(X_{I} \leq x\right)$ and the second is the copula that describes the dependence structure between the random variables (Nelsen, 2006, p. 47), (Embrechts, 2009, p. 639), (Durante \& Sempi, 2010, p. 42), (Kemp, 2011, p. 64), (Joe, 2014, p. 7). The decomposition relies on Sklar's theorem, which states that there exists $n$-dimensional copula $C$ such that:

$$
F\left(x_{1}, \mathrm{~K}, x_{n}\right)=C\left(F_{1}\left(x_{1}\right), \mathrm{K}, F_{n}\left(x_{n}\right)\right) \forall x \in R^{n} .
$$

If marginal cumulative distribution functions $F_{1}, \mathrm{~K}, F_{n}$ are continuous then $C$ is unique.

According to Durante and Jaworski (2010, p. 555), 'There is contagion from market $X$ to market $Y$ if the conditional copula of the market returns $X$ and $Y$, when $X$ is smaller than certain quantile, dominates the conditional copula when $X$ is around its median.' 
Let us assume the two-dimensional case. If $C$ is a copula for the joint distribution for $X_{1}$ and $X_{2}$, then the copula $C_{[\alpha, \beta]}$ is a copula of a conditional distribution of the pair $X_{1}$ and $X_{2}$, given that:

$$
F_{1}\left(X_{1}\right) \in[\alpha, \beta]
$$

Following Durante and Jaworski (2010, p. 555) there is a non-linear contagion - co-movement effect relative to intervals $[\alpha, \beta]$ and $[\gamma, \delta], 0 \leq \alpha<\beta \leq \gamma<\delta \leq 1$, when copula $C_{[\alpha, \beta]}$ dominates over $C_{[\gamma, \delta]}$ with respect to concordance order (the higher the copula values, the more intense the dependence), i.e.:

$$
\forall p \in[0,1]^{2} C_{[\alpha, \beta]}(p) \geq C_{[\gamma, \delta]}(p) \text { and } \exists p_{0} \in[0,1]^{2} C_{[\alpha, \beta]}\left(p_{0}\right)>C_{[\gamma, \delta]}\left(p_{0}\right)
$$

Referring once again to Figure 1 we simply compare conditional copula values for each value 'stripe' and therefore conclude that a higher copula value marks stronger interdependence. The above-defined non-linear contagion effect does not depend on marginal distribution. In addition, the copulas act independently whenever we work on indexes, prices or logarithmic returns. The practical problem in this approach is that copula values must be verified at each point.

Despite the very strong relation between comonotonic random variables, there will be no contagion effect, as their interdependence, although strong, remains stable.

However, it is relatively difficult to estimate copula values, so it is more convenient to compare a copula-dependent measure like Spearman rho or Kendall tau constructing thus a contagion index $d$ :

$$
d=\rho\left(\left\{x_{t}: t \in A\right\}\right)-\rho\left(\left\{x_{t}: t \in B\right\}\right),
$$

where $\rho$ refers to the correlation coefficient (Spearman or $\tau$ Kendall).

\section{CONTAGION VERSUS DIVERGENCE, THE TOY MODEL}

Let $X_{t} Y_{t}$ and $Z_{t}$ be the daily changes of the yields of sovereign debts of three countries, respectively $\mathrm{X}, \mathrm{Y}$ and $\mathrm{Z}$. X represents a country with a strong economy (a leading player), Y a country with economy shaken by a crisis and $\mathrm{Z}$ a "safe haven". Note that when the rating of a given country is de- 
creasing then the prices of government securities are also decreasing but the yields are increasing. We present here a simplified "toy" model which illustrates the interdependence between daily changes of yields. We would like to capture two panic-driven effects. The first one is a standard one, due to some internal problems the global investors lose the confidence in bonds issued by "the leading player" $\mathrm{X}$ and start selling them, which results in a decrease of the price and increase of yields. This causes an anxiety between the "the dependent player" $Y$ bondholders and they start to close their positions although there are no direct "risks" as regards $\mathrm{Y}$.

The second one has a more complicated nature. The global investors lose confidence in "the local player" $\mathrm{Y}$, close their positions in bonds issued by $\mathrm{Y}$ and move their wealth to the safe heaven $\mathrm{Z}$. Thus, although there are no internal reasons, the prices of bonds issued by $\mathrm{Z}$ are going up and yields down.

We consider a three factor model. The exogenous variables (risk factors) are $\varepsilon^{i}, \mathrm{i}=1,2,3$. For simplicity we assume that they are independent random variables with standard normal distribution $N(0,1)$. We put:

$$
\begin{gathered}
X_{t}=\sigma_{X} \varepsilon_{t}^{1}, \\
Y_{t}=\sigma_{Y} \varepsilon_{t}^{2}+\delta_{1}\left(\varepsilon_{t}^{1}-0.842\right)^{+}, \\
Z_{t}=\sigma_{Z} \varepsilon_{t}^{3}-\delta_{2}\left(\varepsilon_{t}^{2}-0.842\right)^{+}
\end{gathered}
$$

where $\sigma_{X}, \sigma_{Y}, \sigma_{Z}, \delta_{1}$ and $\delta_{2}$ are positive constants. The strike 0.842 is selected as a $80 \%$ quantile of the standard normal distribution $N(0,1)$.

Note, that under the condition $X_{t}<0.841 \cdot \sigma_{X}$ the daily changes of yields $X_{t}$ and $Y_{t}$ are independent, while under the condition $X_{t}>0.841 \cdot \sigma_{X}$ the daily changes $X_{t}$ and $Y_{t}$ are positively dependent.

Similarly, under the condition $\varepsilon_{t}^{2}<0.841 \cdot \sigma_{X}$ the daily changes $Y_{t}$ and $Z_{t}$ are independent, while under the condition $\varepsilon_{t}^{2}>0.841 \cdot \sigma_{X}$ the daily changes $Y_{t}$ and $Z_{t}$ are negatively dependent.

Hence our toy model is capturing the contagion between $X$ and $Y$, and divergence between $\mathrm{Y}$ and $\mathrm{Z}$.

Basing on the toy model, the figure 2 and figure 3 present simulated scatter plots from the bivariate margins of the trivariate copula of $(\mathrm{X}, \mathrm{Y}, \mathrm{Z})$. For simulation we assumed the values for $\sigma_{X}=\sigma_{Y}=\sigma_{Z}=0.1$, whereas $\delta_{1}=0.3$ and $\delta_{2}=0.4$. 
Please note, that the concentration of the points at the upper right corner of the first scatterplot (see figure 2) indicates that the dependence between extreme value is bigger than the one between moderate values. Similar effect can be seen on the scatterplot in figure 3 . The difference is that in the former case the extra dependence is between the big values of $X$ and $Y$ (contagion effect) while in the latter the extra dependence is for the big values of $\mathrm{Y}$ and small values of $\mathrm{Z}$.

\section{CONTAGION AND DIVERGENCE AT THE BOND MARKET}

The formal definition of contagion and divergence depends whether we deal with bond prices or yields. In the first case contagious is the drop of the prices hence we compare the lower tail and median part. In the second description contagious is the increase of yields hence we compare the upper tail and median. We will follow the approach presented in Durante and Jaworski (2010, p. 551) and Jaworski and Pitera (2014, p. 303) adjusted to yield description. Instead of lower tail we consider the upper tail of the distribution. We restate the definition.

Let $X_{t}$ and $Y_{t}$ be the daily changes of yield-based indices of markets $\mathrm{X}$ and $\mathrm{Y}$. We assume that in a given period of time they are stationary.

Let $C_{[a, b]}$ denote the copula of the conditional distribution of $\left(X_{t^{\prime}} Y_{t}\right)$ under the condition $F_{X}\left(X_{t}\right) \in[a, b]$.

Definition 1.

We say that there is contagion from market $X$ to market $Y$ with respect to intervals $[1-\alpha, 1]$ and $\left[\beta_{1}, \beta_{2}\right]$, if the conditional copulas $C_{[1-\alpha, 1]}$ and $C_{[\beta 1, \beta 2]}$ differ at least at one point, and the first one dominates in concordance ordering the second one, i.e.:

$$
\forall(u, v) \in[0,1]^{2} C_{[1-\alpha, 1]}(u, v) \geq C_{\left[\beta_{1}, \beta_{2}\right]}(u, v) .
$$

We say that there is divergence between market $X$ and market $Y$ with respect to intervals $[1-\alpha, 1]$ and $\left[\beta_{1}, \beta_{2}\right]$, if the conditional copulas $C_{[1-\alpha, 1]}$ and $C_{[\beta 1, \beta 2]}$ differ at least at one point, and the second one dominates the first one, i.e.:

$$
\forall(u, v) \in[0,1]^{2} C_{[1-\alpha, 1]}(u, v) \leq C_{\left[\beta_{1}, \beta_{2}\right]}(u, v) .
$$


The comparison of copulas in concordance ordering, when we have only their estimates based on empirical data, is rather challenging. Therefore we switch to concordance measures. We choose Spearman $\rho$. Furthermore we reduce the number of parameters. Since the distributions of daily changes are (nearly) symmetric in the median part, we introduce a new parameter $\beta \in(0.5,1)$ and put $\beta_{2=} \beta$ and $\beta_{1}=1-\beta$. Next, to avoid the loss of empirical data or the counting of some of them twice, we put $\alpha=1-\beta_{1}=\beta$. This leads to the following definition of a contagion index:

\section{Definition 2.}

Let $C$ be a copula and $\beta \in(0.5,1)$.

$\Delta_{\beta}(C)=\rho\left(C_{[\beta, 1]}\right)-\rho\left(C_{[1-\beta, \beta]}\right)$,

where $\rho$ denotes the Spearman rank correlation.

The choice of $\beta$ is a more subtle problem. To avoid possible random fluctuations, in Durante, Foscolo, Jaworski and Wang (2014, p. 4025; 2015, p. 219), it was proposed to measure the set of $\beta \mathrm{s}$ for which the index is positive. However, it is recommended to follow the approach proposed in Jaworski and Pitera (2014, p. 308), based on the paradigm that there is no contagion for Gaussian distributions, namely, for Gaussian copula $\Delta_{\beta}$ is changing sign for $1-\beta \approx 0.21$ (compare Jaworski and Pitera (2014, p. 308)). It is positive for a smaller median part and negative for bigger. Thus we selected $\beta=0.8$. To reduce the impact of the fluctuations, due to the random nature of our data, we apply the triangular average of empirical estimates:

$$
\Delta=\frac{1}{4}\left(\widehat{\Delta_{0.82}}+2 \widehat{\Delta_{0.8}}+\widehat{\Delta_{0.78}}\right),
$$

where

$$
\widehat{\Delta_{\beta}}=\widehat{\rho_{[\beta, 1]}}-\widehat{\rho_{[1-\beta, \beta]}} \text {. }
$$

Here $\widehat{\left.\rho_{\beta 1, \beta 2}\right]}$ denotes the Spearman rank correlation of truncated empirical data.

Note that both the contagion index and its empirical estimate do not depend on marginal distribution of daily changes of bonds yields. They extract "the pure dependence". The positive values indicate that the co-movements are 
stronger and more often, when the price of the first bond drops significantly. The negative values indicate that the movements in opposite direction are stronger and more often, when the price of the first bond drops significantly. In the first case we observe contagion, in the second divergence.

\section{EMPIRICAL ANALYSIS}

We took under the consideration Thomson/Reuters yield indices for bonds of different maturities issued in USA, Germany, Japan, Australia, Poland, Italy and Portugal for the period of time from 2004-11-19 to 2014-11-17. We compare the market behavior before and after the change of regime implied by the financial crisis. As a breaking point we select 2009-12-31. The choice is affected by empirical analysis of Eurozone bonds, where at the end of 2009 the final break is observed (see figure 4 for quotations referring to Germany and Portugal).

In tables 1 and 2 we present values of contagion index $\Delta$ for years 2004-2009 and 2010-2014, calculated for the daily changes of the Thomson/Reuters yield indices. Contagion or divergence goes from the indices in left column to indices in the first row. Note that after the change of regime, the values are quite different. On Figures from 5 to 16 we show the visualization of the data given in tables.

The bar charts (figures 5 to 16) illustrate the results presented in tables 1 and 2. We may conclude, that bars going upward illustrate contagion effect, while bars directed downwards reflect the divergence. Basing on our sample, we can note that the divergence effect prevails over contagion. It mirrors the fact, there was no worldwide retreat from bond markets as a result of crisis. The threat of sovereign insolvency during the crises was limited only to selected countries. The sample includes safe haven countries (Germany, US, Australia), emerging markets (Poland), troubled ones (Portugal, Italy) and Japan. As it was already mentioned, the sample has been selected heuristically. As our methodology complies with the portfolio theory, we do not concentrate on fundamental explanation for the obtained results, but rather try to capture statistical relationship between the time series using defined measures. Generally speaking, there was some contagion before the crisis, although divergence prevailed. After outbreak of the crisis, we can see increase of contagion. Graphic comparison between pre-crisis and post-crisis observation may be seen at the diagrams (figure 17 and figure 18). We can see the rise of shock transmission referring to Far East Asia sovereign bonds (Japan, Australia) after the outbreak 
of the crisis. The most characteristic case out of our sample seems to be Japan. Before the crisis there was negative interdependency between Japanese and other countries' sovereign bonds. At present, among our sample Japan produces more danger for an international bond markets in terms of contagion than Italy or Germany. Basing on our countries selection, we found out that there is more divergence among the EMU countries than between the EMU sovereigns and Japanese or the US bonds. The analysis gives us also an insight into the term structure of interest rates reaction following shock. We used the bonds representative for the short end-, middle section- and long end of each government yield curve. Before the crisis contagion effect affected predominantly long term bonds. After the Lehman collapse we may observe the reaction along the whole government yield curve.

The applied contagion index enables intra-country contagion analysis. Contagion between bonds of a single issuer representing extreme ends of the government yield curve is tantamount to yield curve twist movement. Divergence within the bonds of the same issuer with different maturity results in parallel shift. If the bond yield at the middle of yield curve diverge relative to other yields, it means that we face the yield curve butterfly movement (results in change of the yield curve convexity). Of course the parallel shift dominates. However when it comes to Polish government debt, investors tend to shift money between short term and long term bonds and the yield curve finally twists.

There are some more interesting observations: When we look at Figures 9-10 we may observe that divergence effect between Polish, German and the US markets in years 2004-2009 changed into contagion effect in period 2010-2012. The same effect can be seen for Japanese market (figures 11-12). The divergence effect between Japanese and German bonds changed into convergence effect. What regards German market, we observe strong divergence towards Italy and Japan. This was to disappear later on while the divergence towards Australia market turned into contagion. There was, in turn strong divergence form Australian to German, Italian and Polish markets in years 2004-2009 which was to disappear in years 2010-2014.

\section{THE OUTCOME OF THE RESEARCH PROCESS AND CONCLUSIONS}

The latest research puts a lot of attention on contagion effect. However, there is a kind of a variety among contagion effect definitions. It is important to stress, that the contagion does not simply equal strong interdependency: the conta- 
gion require change of interdependency level (significant rise) in times of contraction. In this aspect classic portfolio theory may lead to catastrophic risk underestimation as it captures normal market conditions, i.e. it considers the value range for random variables in the middle of their distributions, thus ignoring extreme events. What is more, not only the extreme events probability but also the linear as well as non-linear interdependency increase must be taken into account.

There is a robust methodology on modeling the relationship between multidimensional random variables with special focus on contagion effect. The paper presents and somehow places these techniques in some sort of order with a following approach forged by Durante and Jaworski (2010, p. 551), Jaworski and Pitera (2014, p. 303), Durante and Foscolo (2013, p. 319) and Durante et al. (2014, p. $4023 ; 2015$, p. $217 ; 2017$, p. 1). The copula theory is worth the attention, as it captures non-linear contagion effects, so demanded by the practitioners (Embrechts, 2009, p. 639).

The article proposes definition and measure for bond divergence effect, which opposite to contagion effect. Therefore our research puts an equal accent on both contagion and divergence effect on bond sovereign bond markets as we see the latter effect somehow overlooked in literature and research.

We conducted our calculations basing on sovereign bonds representative for safe haven countries (Germany, US, Australia), emerging markets (Poland), troubled ones (Portugal, Italy) and Japan.

We found some contagion before the crisis, although divergence prevailed. After the outbreak of recent crisis contagion increased. Prior to that, contagion affected predominantly long term bonds. After Lehman collapse we may observe contagion along the whole government yield curve.

Paradoxically, judging from our sample analysis, one can find an increase of divergence between the EMU countries. This may serve as another evidence for the thesis that introduction of the European Monetary Union contributed more to divergence than convergence in bond yields. Germany and Australia play the role of safe havens in our sample. During contraction times, Japanese investors retreat from bond markets shifting their money to Australian and to some extend into US-sovereign debt.

The advantage of the proposed method is that there is no need of subjective subdivision of the time axle into the calm and crisis periods. Instead, one just compares the size of changes which means it is enough to look at the distribution of empirical values. 
Figure 2. Scaterplot of 1000 points simulated from the copula of $X$ and $Y$ from the toy model

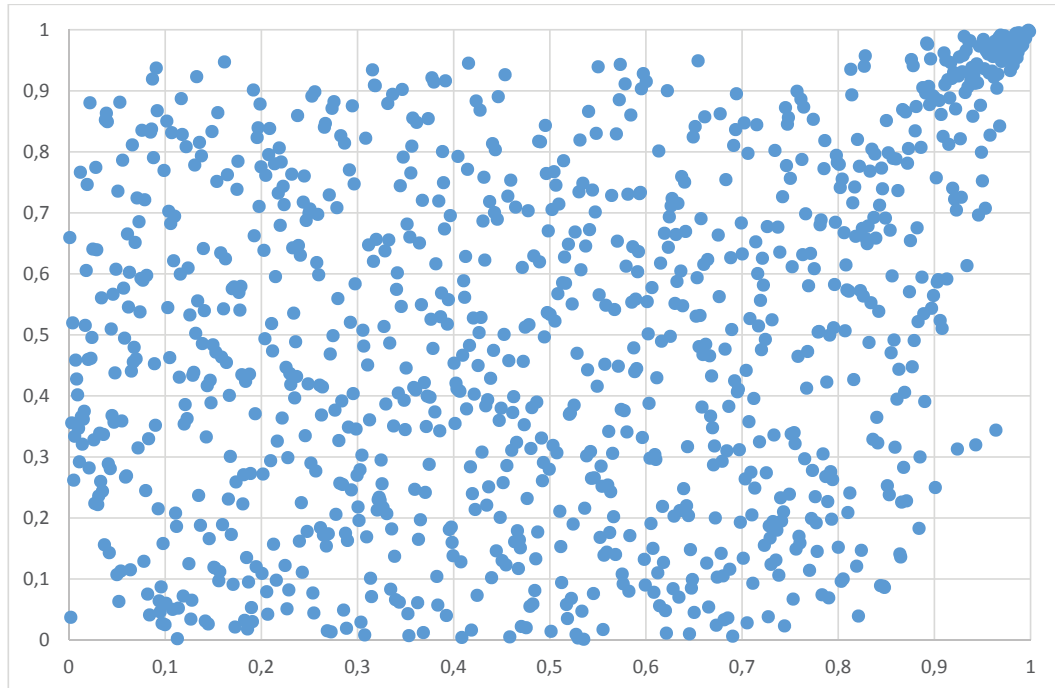

S o u r c e : own calculations.

Figure 3. Scaterplot of 1000 points simulated from the copula of $Y$ and $Z$ from the toy model

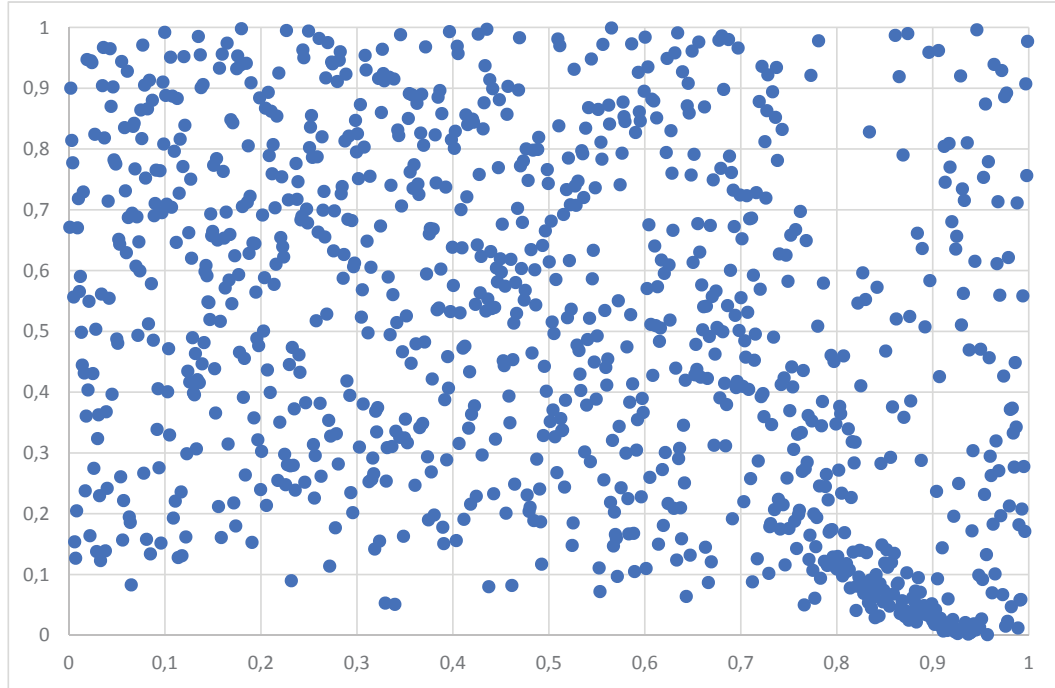

S o u r c e : own calculations. 
Figure 4. Yields of German 3 year bonds and Portugal 5 year bonds

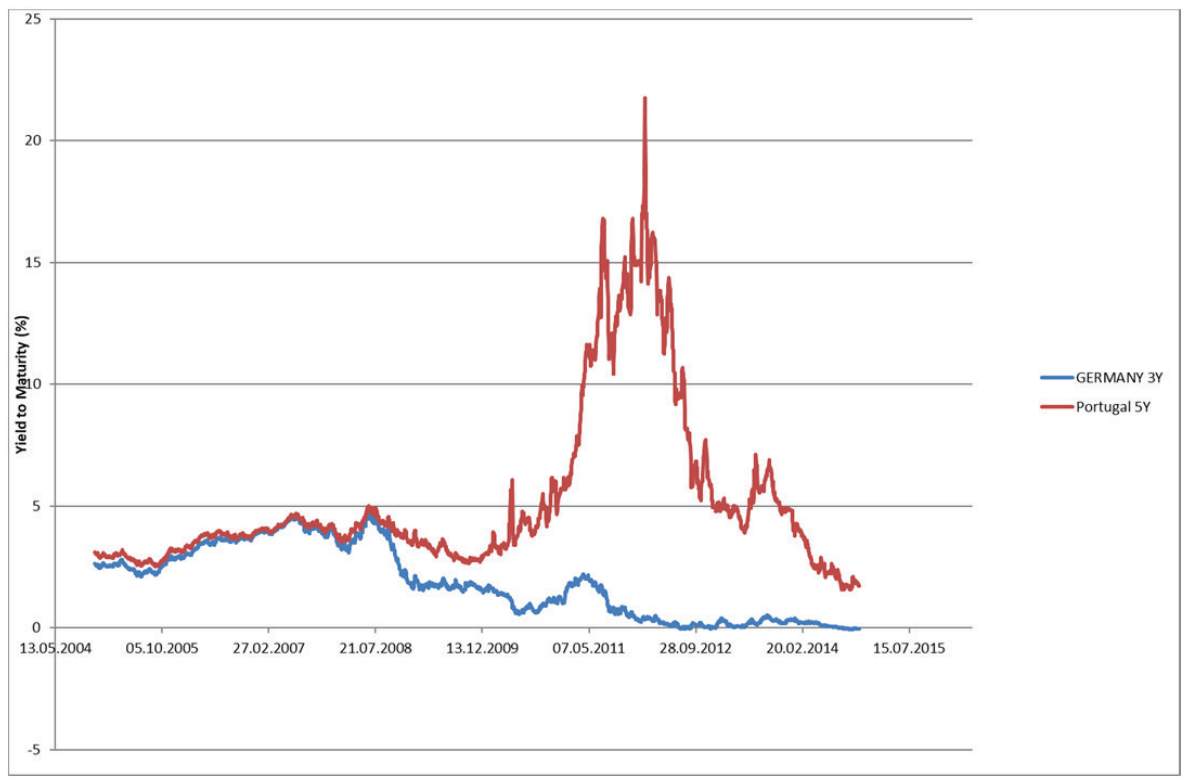

S o u r c e : own calculations based on Thomson/Reuters data.

Table 1. Contagion index $\Delta$ for years 2004-2009

\begin{tabular}{|c|c|c|c|c|c|c|c|c|c|}
\hline$\Delta$ & G10Y & G5Y & G3Y & I10Y & $15 Y$ & I3Y & PI10Y & PI5Y & PI3Y \\
\hline GERMANY $10 Y$ & 0 & -0.06 & -0.11 & -0.28 & -0.17 & -0.16 & 0.02 & 0.07 & 0.08 \\
\hline GERMANY $5 Y$ & -0.04 & 0 & -0.04 & -0.24 & -0.1 & -0.13 & -0.08 & -0.05 & -0.01 \\
\hline GERMANY $3 Y$ & -0.13 & -0.09 & 0 & -0.21 & -0.1 & -0.14 & -0.04 & -0.08 & 0.02 \\
\hline Italy $10 \mathrm{Y}$ & -0.16 & -0.17 & -0.15 & 0 & -0.09 & -0.08 & 0.13 & 0.14 & 0.06 \\
\hline Italy 5Y & -0.15 & -0.12 & -0.13 & -0.17 & 0 & -0.07 & -0.11 & -0.05 & -0.02 \\
\hline Italy $3 Y$ & -0.2 & -0.17 & -0.16 & -0.23 & -0.15 & 0 & -0.21 & -0.15 & -0.14 \\
\hline Poland 10Y & -0.09 & -0.12 & -0.1 & -0.04 & -0.08 & -0.08 & 0 & -0.05 & 0.03 \\
\hline Poland $5 Y$ & -0.11 & -0.1 & -0.07 & -0.08 & -0.02 & -0.02 & -0.07 & 0 & 0.06 \\
\hline Poland 3Y & -0.01 & -0.03 & 0 & 0.01 & 0.08 & 0.05 & -0.03 & -0.02 & 0 \\
\hline Japan 10Y & 0.01 & 0.02 & 0.02 & 0.04 & 0.06 & 0.04 & 0 & -0.04 & 0 \\
\hline Japan $5 Y$ & -0.07 & -0.08 & -0.07 & -0.02 & -0.01 & 0 & -0.02 & -0.04 & 0.01 \\
\hline Japan $3 Y$ & -0.12 & -0.12 & -0.1 & -0.09 & -0.04 & -0.04 & -0.08 & -0.07 & -0.03 \\
\hline
\end{tabular}


Table 1. Contagion index $\Delta$ for years 2004-2009

\begin{tabular}{|l|c|c|c|c|c|c|c|c|c|}
\hline \hline \multicolumn{1}{|c|}{$\boldsymbol{\Delta}$} & G10Y & G5Y & G3Y & I10Y & I5Y & I3Y & PI10Y & PI5Y & PI3Y \\
\hline \hline USA 10Y & -0.12 & -0.09 & -0.09 & -0.16 & -0.12 & -0.13 & -0.13 & -0.21 & -0.13 \\
\hline USA 5Yg & -0.08 & -0.04 & -0.02 & -0.07 & -0.03 & -0.04 & -0.13 & -0.18 & -0.06 \\
\hline USA 2Y & 0.01 & 0.03 & 0.05 & 0.04 & 0.1 & 0.07 & -0.07 & -0.08 & -0.01 \\
\hline Portugal 5Y & -0.15 & -0.13 & -0.1 & -0.18 & -0.11 & -0.11 & -0.05 & -0.05 & -0.04 \\
\hline AUSTRALIA 10Y & -0.06 & -0.08 & -0.09 & -0.13 & -0.08 & -0.05 & -0.09 & -0.1 & -0.05 \\
\hline AUSTRALIA 5Y & -0.12 & -0.14 & -0.16 & -0.16 & -0.16 & -0.15 & -0.08 & -0.1 & -0.06 \\
\hline AUSTRALIA 3Y & -0.12 & -0.16 & -0.17 & -0.15 & -0.17 & -0.16 & -0.07 & -0.1 & -0.08 \\
\hline \hline
\end{tabular}

\begin{tabular}{|c|c|c|c|c|c|c|c|c|c|c|}
\hline$\Delta$ & J10Y & J5Y & J3Y & U10Y & U5Y & U2Y & Pt5Y & A10Y & A5Y & A3Y \\
\hline GERMANY $10 Y$ & -0.08 & -0.1 & -0.12 & -0.05 & -0.1 & -0.1 & -0.14 & 0.05 & 0.02 & 0.01 \\
\hline GERMANY $5 Y$ & -0.14 & -0.15 & -0.13 & -0.07 & -0.07 & -0.06 & -0.08 & -0.08 & -0.1 & -0.1 \\
\hline GERMANY $3 Y$ & -0.15 & -0.13 & -0.1 & -0.06 & -0.03 & -0.01 & -0.06 & -0.08 & -0.11 & -0.11 \\
\hline Italy $10 Y$ & -0.05 & -0.09 & -0.1 & -0.08 & -0.07 & -0.06 & -0.11 & -0.1 & -0.06 & -0.04 \\
\hline Italy $5 Y$ & -0.1 & -0.09 & -0.11 & -0.05 & -0.03 & -0.04 & -0.12 & -0.05 & -0.08 & -0.08 \\
\hline Italy $3 Y$ & -0.15 & -0.13 & -0.13 & -0.03 & -0.01 & -0.03 & -0.16 & -0.08 & -0.12 & -0.12 \\
\hline Poland 10Y & 0.04 & -0.01 & -0.06 & 0 & -0.04 & -0.03 & -0.09 & 0.07 & 0.04 & 0.03 \\
\hline Poland 5Y & 0.05 & 0.04 & 0.03 & -0.11 & -0.14 & -0.09 & -0.08 & 0.06 & 0.02 & 0 \\
\hline Poland $3 Y$ & 0.01 & -0.04 & -0.02 & -0.04 & -0.04 & -0.02 & 0.03 & 0.04 & -0.02 & -0.04 \\
\hline Japan 10Y & 0 & 0.03 & 0 & 0.03 & 0.02 & 0.01 & 0.05 & 0.04 & 0.06 & 0.08 \\
\hline Japan $5 Y$ & -0.03 & 0 & -0.01 & -0.1 & -0.1 & -0.12 & -0.03 & -0.02 & -0.03 & -0.02 \\
\hline Japan $3 Y$ & -0.17 & -0.16 & 0 & -0.06 & -0.07 & -0.07 & -0.08 & -0.05 & -0.06 & -0.03 \\
\hline USA 10Y & 0.03 & 0.06 & 0.05 & 0 & -0.08 & -0.2 & -0.16 & 0.11 & 0.11 & 0.11 \\
\hline USA $5 Y$ & -0.05 & 0.03 & 0.04 & -0.05 & 0 & -0.13 & -0.05 & 0.05 & 0.08 & 0.07 \\
\hline USA $2 Y$ & -0.11 & -0.06 & 0 & -0.16 & -0.08 & 0 & 0.06 & 0.02 & 0.04 & 0.04 \\
\hline Portugal $5 Y$ & -0.13 & -0.1 & -0.1 & -0.04 & -0.01 & -0.04 & 0 & -0.07 & -0.08 & -0.09 \\
\hline AUSTRALIA 10Y & -0.16 & -0.13 & -0.13 & 0.09 & 0.01 & -0.09 & -0.12 & 0 & -0.07 & -0.12 \\
\hline AUSTRALIA 5Y & -0.09 & -0.13 & -0.15 & 0.05 & 0.02 & -0.09 & -0.18 & -0.13 & 0 & -0.01 \\
\hline AUSTRALIA 3Y & -0.09 & -0.11 & -0.14 & 0.07 & 0.04 & -0.05 & -0.18 & -0.19 & -0.02 & 0 \\
\hline
\end{tabular}

S o u r c e : own calculations. 
Table 2. Contagion index $\Delta$ for years 2010-2014

\begin{tabular}{|c|c|c|c|c|c|c|c|c|c|}
\hline$\Delta$ & G10Y & G5Y & G3Y & I10Y & $15 Y$ & $13 Y$ & PI10Y & PI5Y & $\mathrm{PI} Y \mathrm{Y}$ \\
\hline GERMANY 10Y & 0 & -0.13 & -0.12 & -0.06 & -0.07 & -0.01 & -0.12 & -0.16 & -0.11 \\
\hline GERMANY $5 Y$ & -0.19 & 0 & -0.11 & -0.02 & -0.01 & 0.03 & -0.07 & -0.12 & -0.07 \\
\hline GERMANY $3 Y$ & -0.26 & -0.18 & 0 & 0.01 & 0.01 & 0.04 & -0.11 & -0.17 & -0.1 \\
\hline Italy $10 Y$ & -0.3 & -0.28 & -0.27 & 0 & 0.01 & 0.03 & 0 & 0.03 & 0.02 \\
\hline Italy $5 Y$ & -0.25 & -0.24 & -0.23 & -0.04 & 0 & -0.02 & 0 & 0 & 0 \\
\hline Italy $3 Y$ & -0.27 & -0.27 & -0.28 & -0.07 & -0.08 & 0 & -0.01 & 0.02 & -0.02 \\
\hline Poland 10Y & 0.12 & 0.14 & 0.1 & -0.05 & -0.03 & -0.04 & 0 & 0.05 & 0.06 \\
\hline Poland $5 Y$ & 0.11 & 0.09 & 0.03 & -0.01 & -0.02 & -0.04 & 0.04 & 0 & -0.01 \\
\hline Poland $3 Y$ & 0.04 & 0.03 & 0 & -0.07 & -0.02 & -0.04 & -0.09 & -0.1 & 0 \\
\hline Japan 10Y & 0.07 & 0.11 & 0.12 & -0.01 & 0.05 & 0.02 & 0.12 & 0.1 & 0.09 \\
\hline Japan $5 Y$ & 0.01 & 0.06 & 0.09 & 0.06 & 0.05 & 0.05 & 0.09 & 0.1 & 0.04 \\
\hline Japan $3 Y$ & 0.02 & -0.02 & -0.01 & 0.16 & 0.16 & 0.09 & 0.1 & 0.1 & 0.04 \\
\hline USA $10 Y$ & 0.04 & 0.06 & 0.08 & 0.18 & 0.13 & 0.1 & 0.01 & 0.01 & 0.03 \\
\hline USA 5Y & -0.17 & -0.11 & -0.06 & 0.22 & 0.21 & 0.18 & -0.02 & -0.05 & 0.02 \\
\hline USA $2 Y$ & -0.22 & -0.12 & -0.08 & 0.2 & 0.22 & 0.22 & 0 & -0.03 & 0.02 \\
\hline Portugal $5 Y$ & -0.16 & -0.17 & -0.16 & -0.23 & -0.21 & -0.2 & -0.2 & -0.22 & -0.17 \\
\hline AUSTRALIA $10 Y$ & -0.06 & -0.05 & -0.02 & -0.05 & -0.02 & -0.05 & 0.01 & 0.06 & 0.07 \\
\hline AUSTRALIA 5Y & -0.06 & -0.02 & 0.06 & 0 & 0 & -0.01 & 0.05 & 0.06 & 0.06 \\
\hline AUSTRALIA 3Y & -0.06 & -0.03 & 0.03 & 0 & 0.01 & -0.01 & 0.03 & 0.03 & 0.04 \\
\hline
\end{tabular}

\begin{tabular}{|l|c|c|c|c|c|c|c|c|c|c|}
\hline \hline \multicolumn{1}{|c|}{$\boldsymbol{\Delta}$} & J10Y & J5Y & J3Y & U10Y & U5Y & U2Y & Pt5Y & A10Y & A5Y & A3Y \\
\hline \hline GERMANY 10Y & -0.06 & -0.06 & 0.06 & -0.05 & -0.11 & -0.08 & 0.04 & -0.01 & 0 & 0 \\
\hline GERMANY 5Y & 0.01 & -0.01 & 0.07 & -0.11 & -0.15 & -0.11 & -0.03 & 0.15 & 0.16 & 0.16 \\
\hline GERMANY 3Y & -0.03 & -0.03 & 0.07 & -0.12 & -0.14 & -0.12 & 0.01 & 0.1 & 0.11 & 0.12 \\
\hline Italy 10Y & -0.11 & -0.04 & 0.02 & -0.18 & -0.12 & -0.03 & -0.16 & -0.05 & -0.06 & -0.05 \\
\hline Italy 5Y & 0.02 & 0.02 & 0.14 & -0.23 & -0.2 & -0.14 & -0.26 & -0.12 & -0.13 & -0.13 \\
\hline Italy 3Y & 0.02 & -0.02 & 0.03 & -0.2 & -0.15 & -0.08 & -0.25 & -0.12 & -0.15 & -0.16 \\
\hline Poland 10Y & -0.02 & 0.02 & 0.01 & 0.04 & 0.03 & 0.05 & -0.03 & 0 & 0 & 0 \\
\hline Poland 5Y & -0.04 & -0.05 & -0.08 & 0 & 0.02 & 0.08 & 0.01 & 0.03 & 0.04 & 0.05 \\
\hline
\end{tabular}


Table 2. Contagion index $\Delta$ for years 2010-2014

\begin{tabular}{|l|l|l|l|l|l|l|l|l|l|l|}
\hline \hline \multicolumn{1}{|c|}{$\boldsymbol{\Delta}$} & J10Y & J5Y & J3Y & U10Y & U5Y & U2Y & Pt5Y & A10Y & A5Y & A3Y \\
\hline \hline Poland 3Y & 0 & -0.01 & -0.03 & -0.04 & -0.02 & -0.02 & -0.08 & -0.01 & 0 & 0.01 \\
\hline Japan 10Y & 0 & -0.01 & 0.07 & 0.05 & 0.09 & 0.12 & -0.02 & -0.07 & -0.09 & -0.08 \\
\hline Japan 5Y & 0.06 & 0 & 0.24 & -0.06 & -0.05 & -0.04 & 0.08 & -0.12 & -0.15 & -0.16 \\
\hline Japan 3Y & 0.11 & 0.12 & 0 & 0 & 0 & 0.01 & 0.15 & -0.04 & -0.09 & -0.1 \\
\hline USA 10Y & 0.09 & -0.01 & 0.06 & 0 & -0.08 & -0.08 & 0.01 & 0 & -0.02 & -0.04 \\
\hline USA 5Y & 0.07 & 0.02 & 0 & -0.14 & 0 & -0.05 & -0.01 & -0.01 & -0.04 & -0.03 \\
\hline USA 2Y & 0.01 & 0.01 & -0.07 & -0.14 & -0.07 & 0 & 0.04 & -0.01 & 0.03 & 0.04 \\
\hline Portugal 5Y & 0.01 & 0.02 & -0.01 & -0.02 & 0 & 0.09 & 0 & -0.08 & -0.06 & -0.07 \\
\hline AUSTRALIA 10Y & -0.07 & -0.12 & -0.02 & -0.05 & -0.09 & -0.02 & 0.06 & 0 & -0.12 & -0.17 \\
\hline AUSTRALIA 5Y & -0.09 & -0.08 & -0.04 & -0.03 & -0.07 & -0.04 & 0.11 & -0.19 & 0 & -0.04 \\
\hline AUSTRALIA 3Y & -0.15 & -0.14 & -0.09 & -0.01 & -0.06 & -0.03 & 0.1 & -0.25 & -0.06 & 0 \\
\hline \hline
\end{tabular}

S o u r c e : own calculations.

Figure 5. Contagion/divergence from German to other markets, years 2004-2009

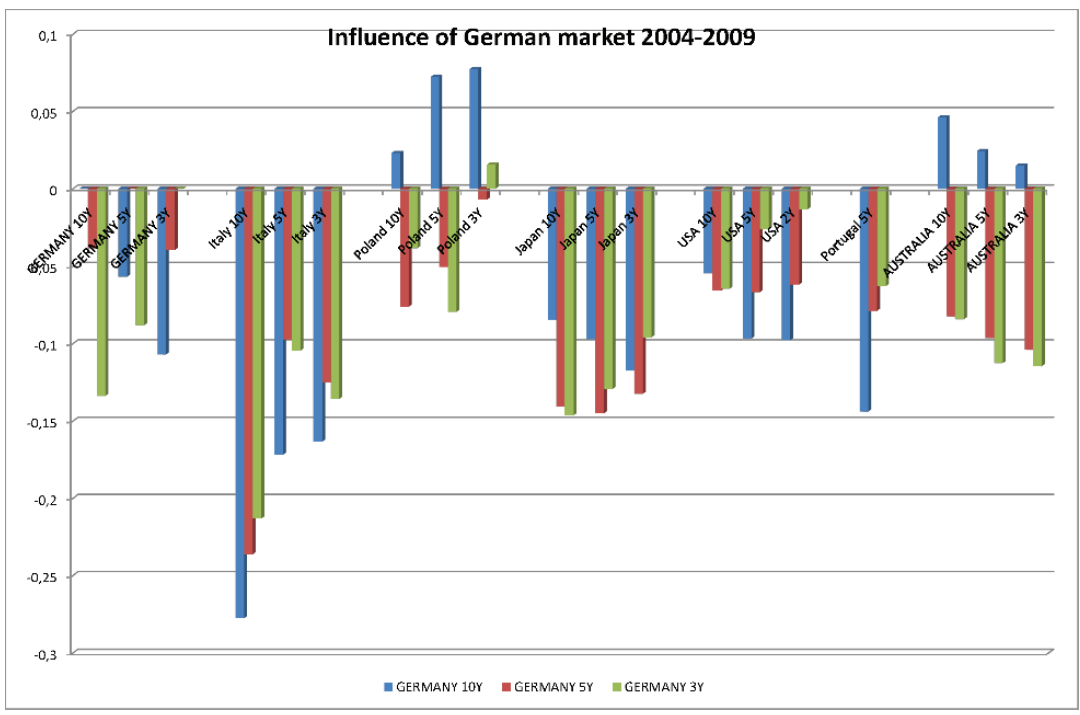

S o u r c e : own calculations. 
Figure 6. Contagion/divergence from German to other markets, years 2010-2014

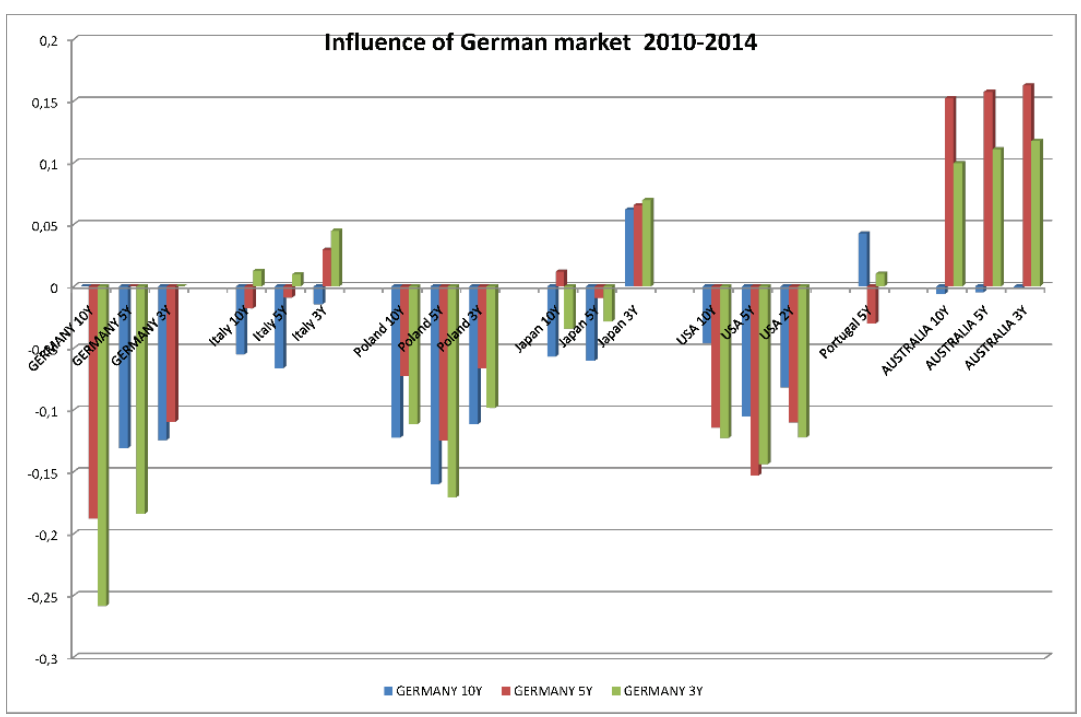

S o u r c e : own calculations.

Figure 7. Contagion/divergence from Italian and Portugal to other markets, years 2004-2009

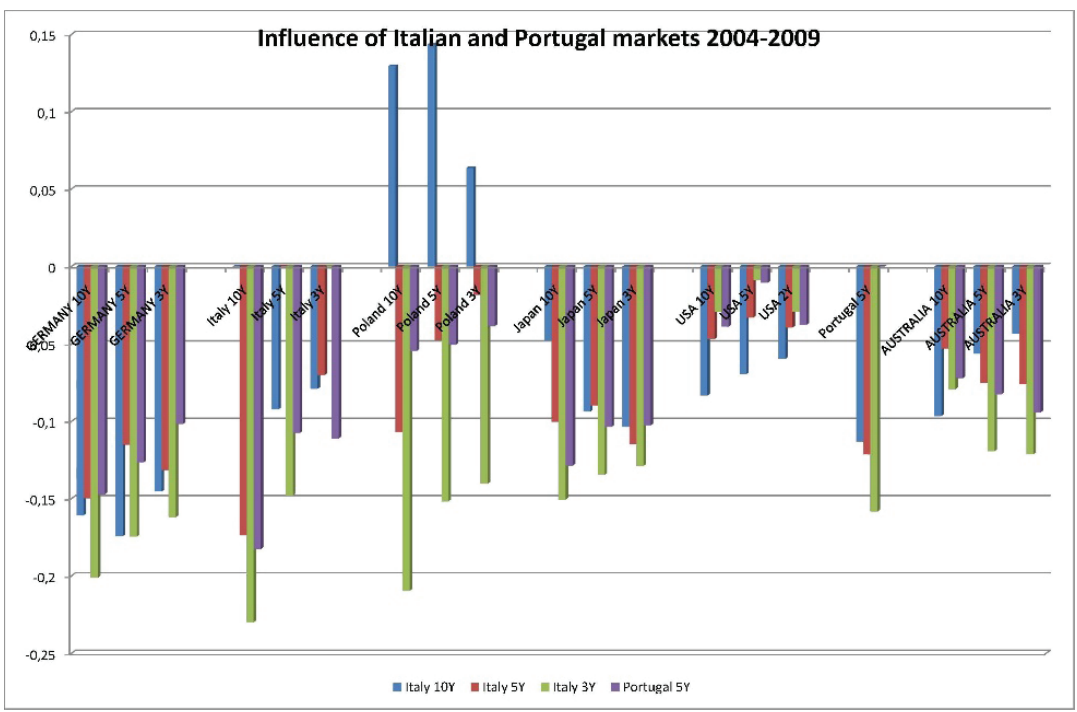

S o u r c e : own calculations. 
Figure 8. Contagion/divergence from Italian and Portugal to other markets, years 2010-2014

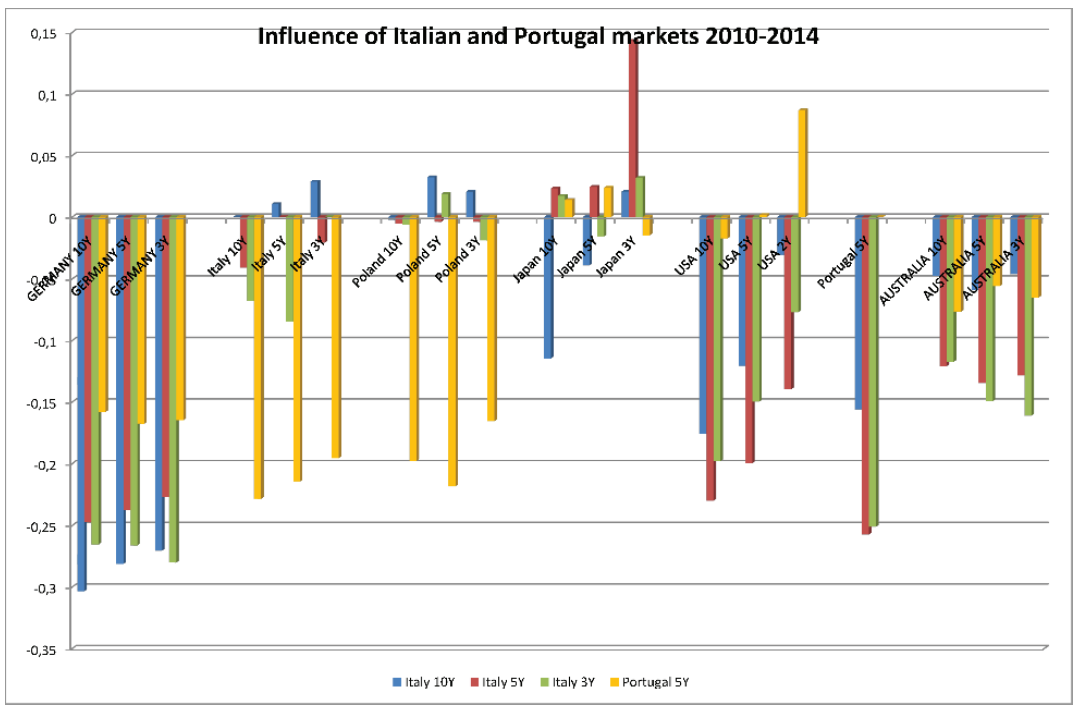

S o u r c e : own calculations.

Figure 9. Contagion/divergence from Polish to other markets, years 2004-2009

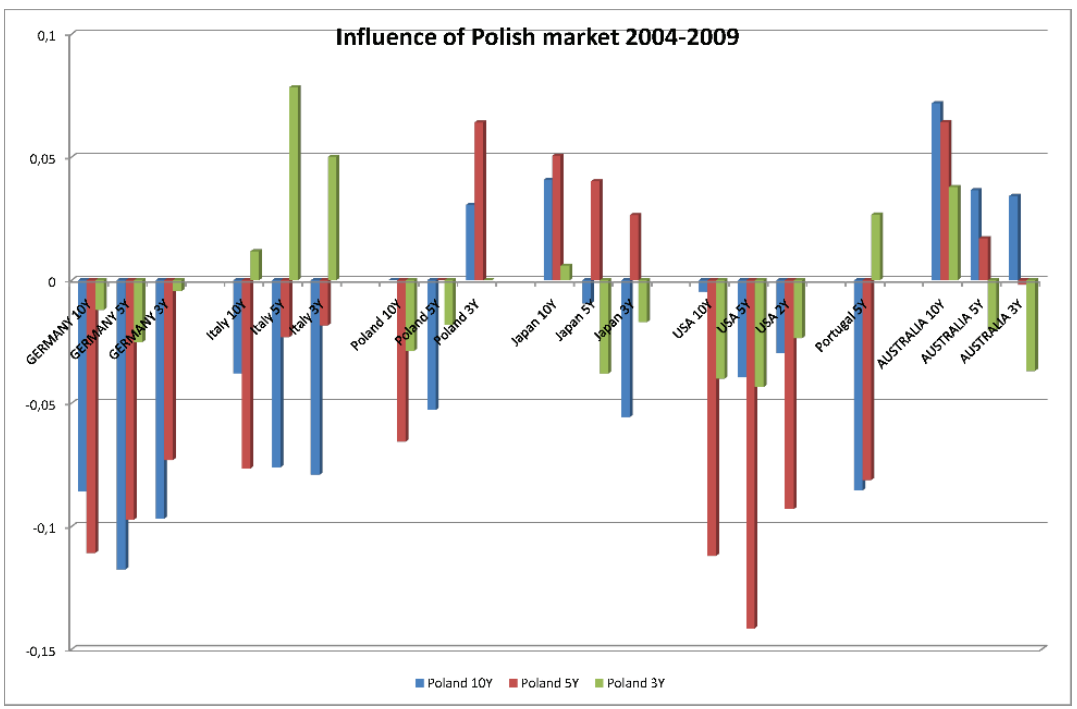

S o u r c e : own calculations. 
Figure 10. Contagion/divergence from Polish to other markets, years 2010-2014

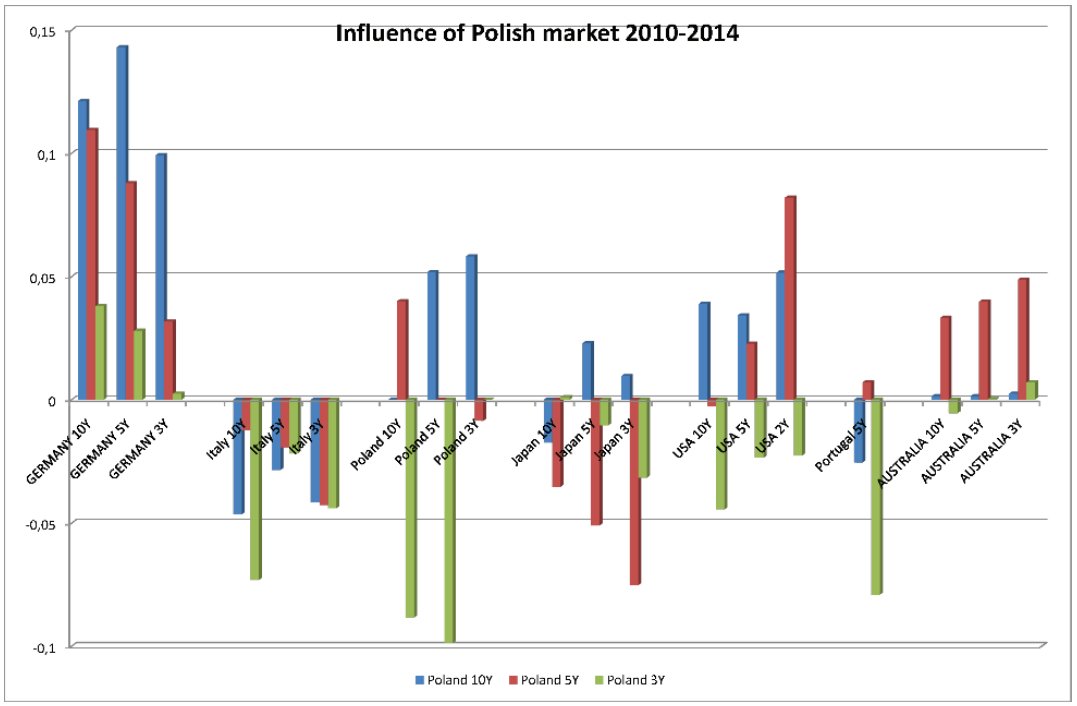

S o u r c e : own calculations.

Figure 11. Contagion/divergence from Japan to other markets, years 2004-2009

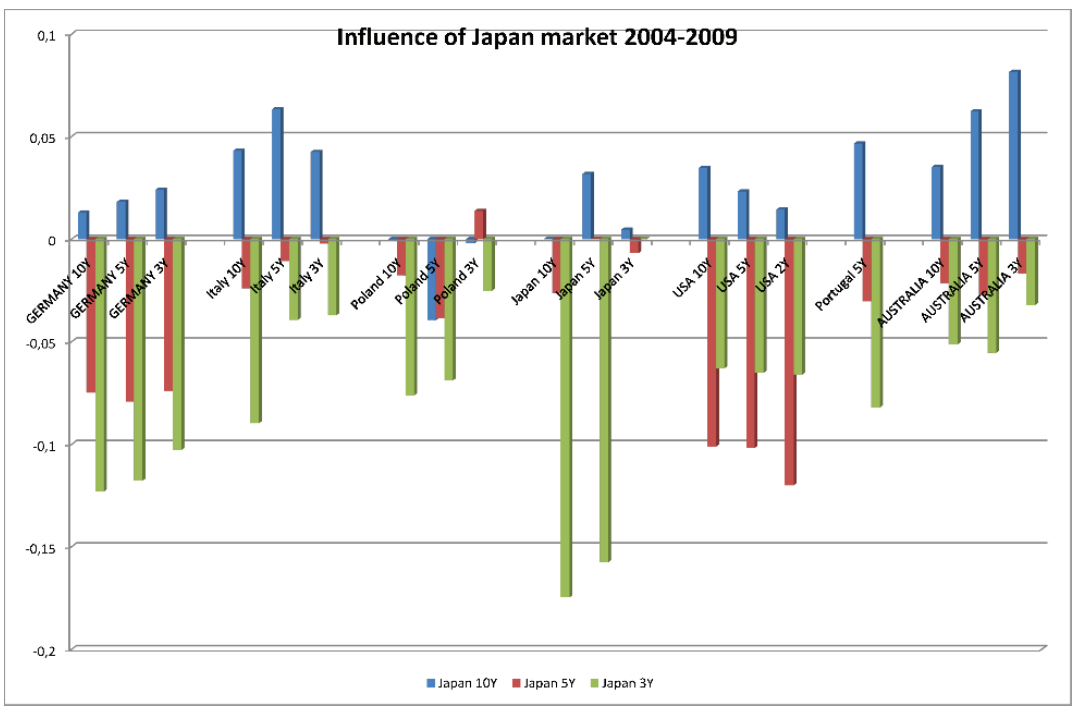

S o u r c e : own calculations. 
Figure 12. Contagion/divergence from Japan to other markets, years 2010-2014

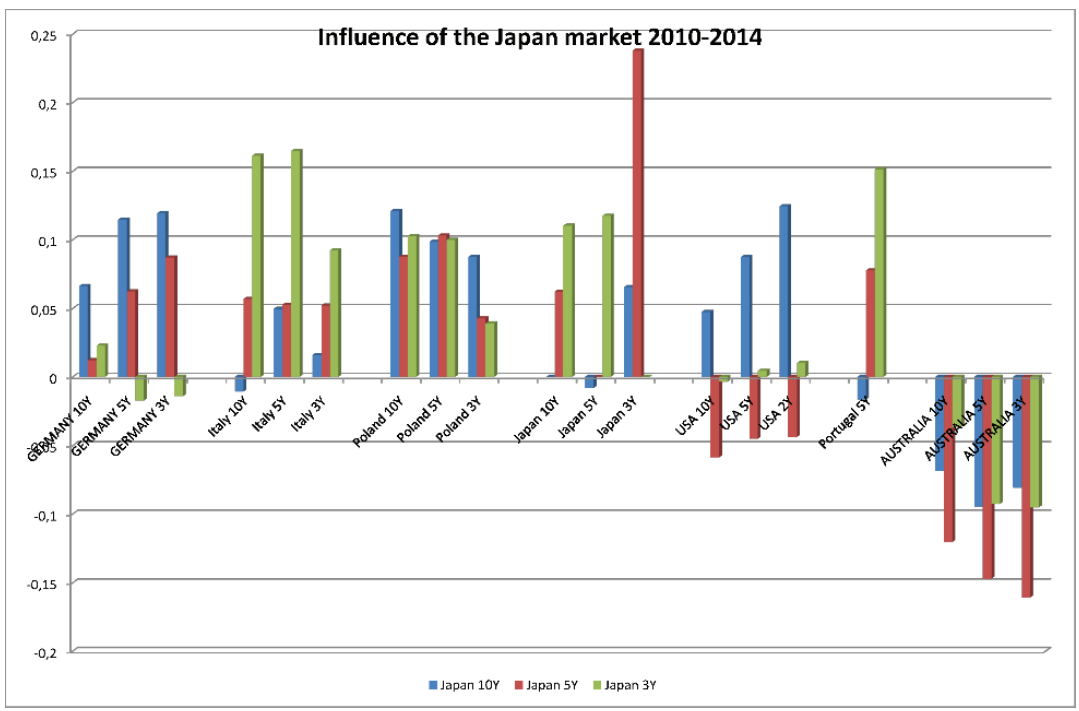

S o u r c e : own calculations.

Figure 13. Contagion/divergence from USA to other markets, years 2004-2009

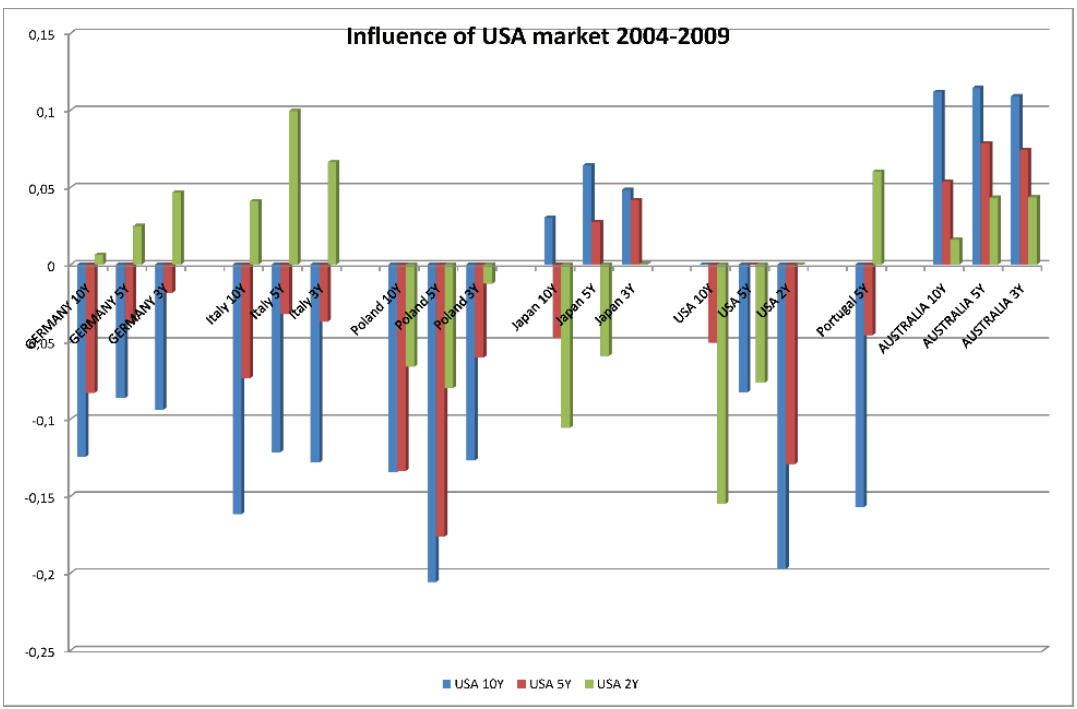

S o u r c e : own calculations. 
Figure 14. Contagion/divergence from USA to other markets, years 2010-2014

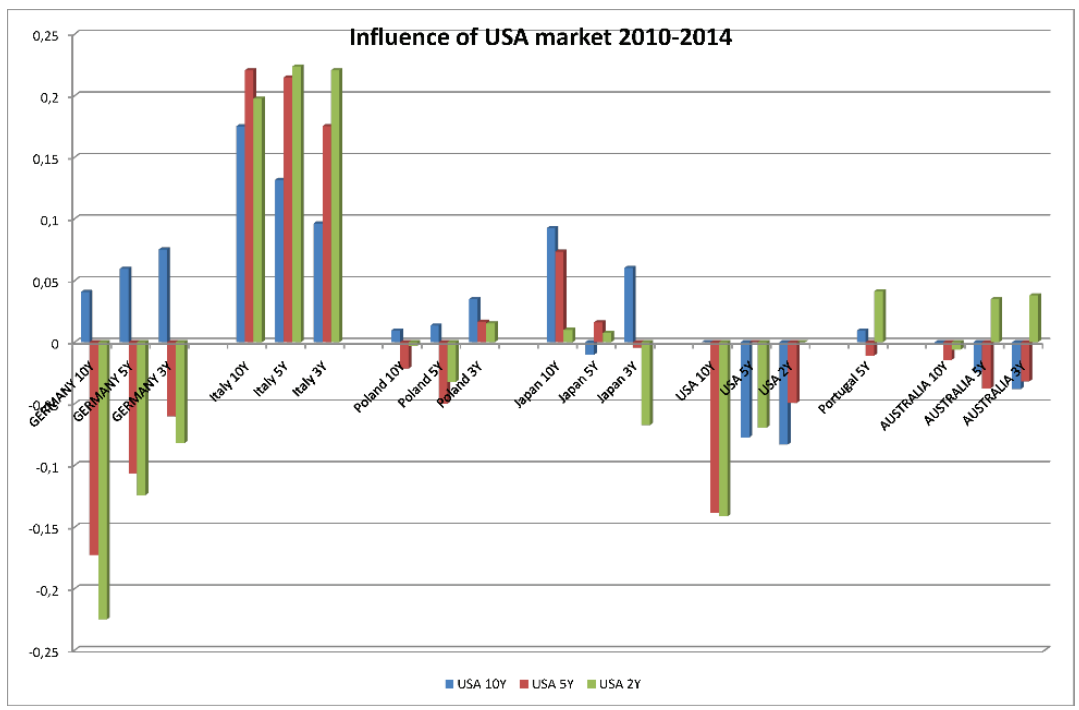

S o u r c e : own calculations.

Figure 15. Contagion/divergence from Australian to other markets, years 2004-2009

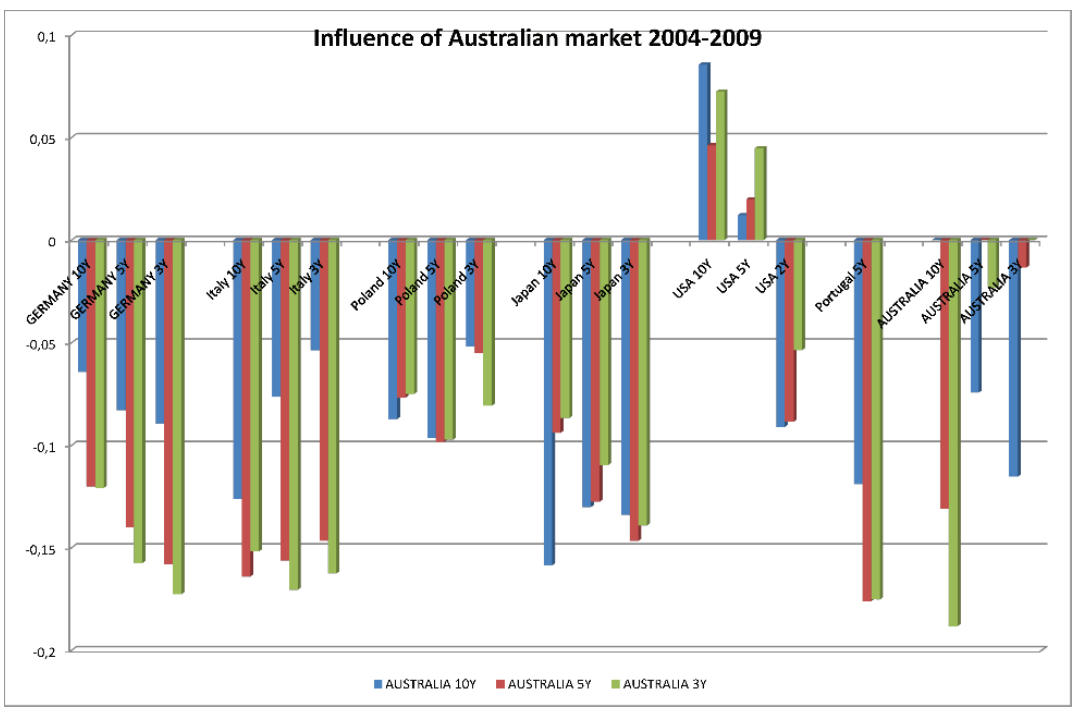

S o u r c e : own calculations. 
[64]

Figure 16. Contagion/divergence from Australian to other markets, years 2010-2014

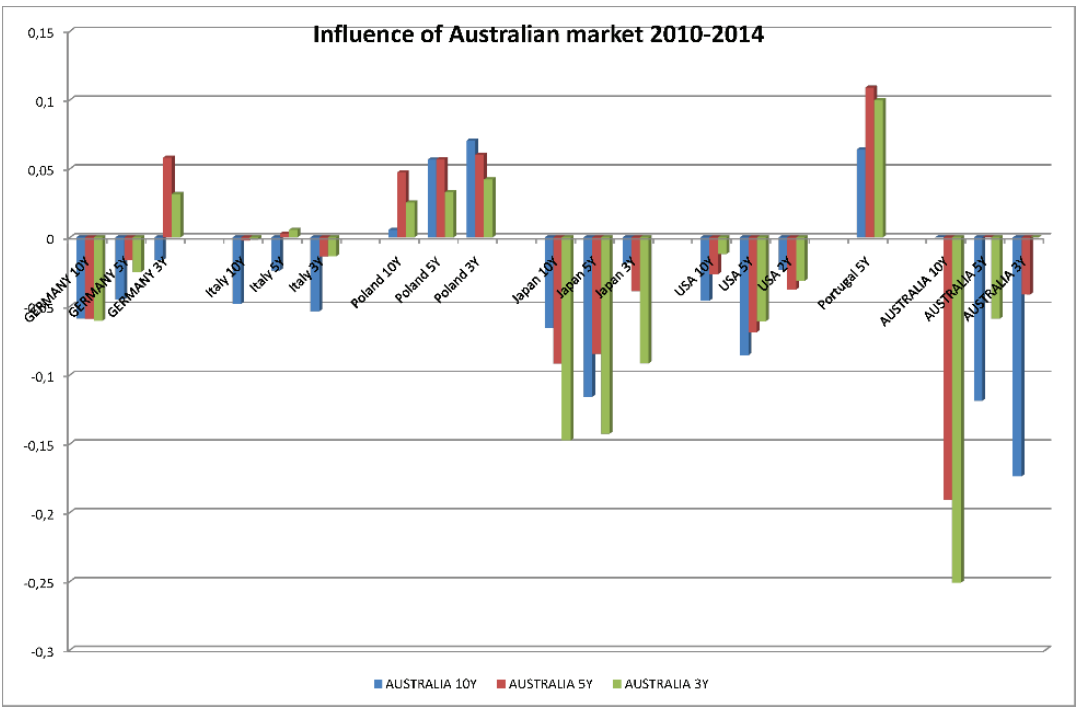

S o u r c e : own calculations. 
Figure 17. Contagion diagram 2004-2014

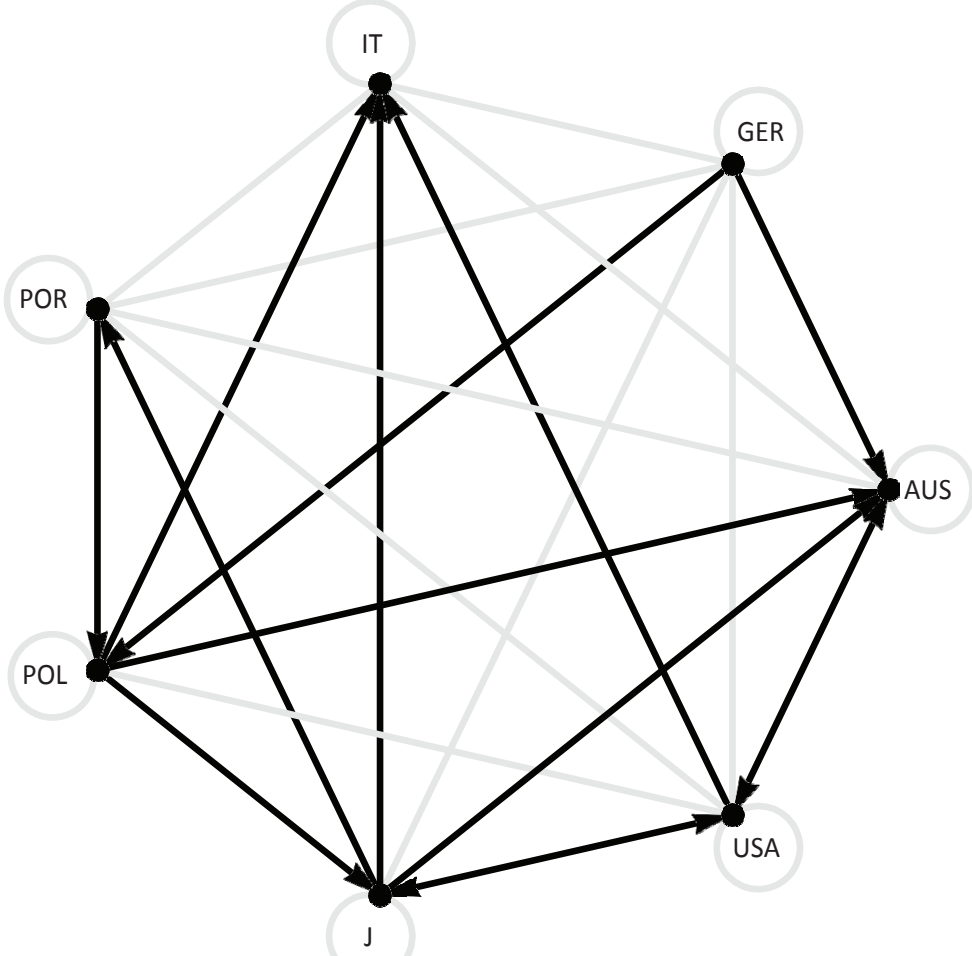

S o u r c e : own calculations. 
Figure 18. Contagion diagram 2009-2014

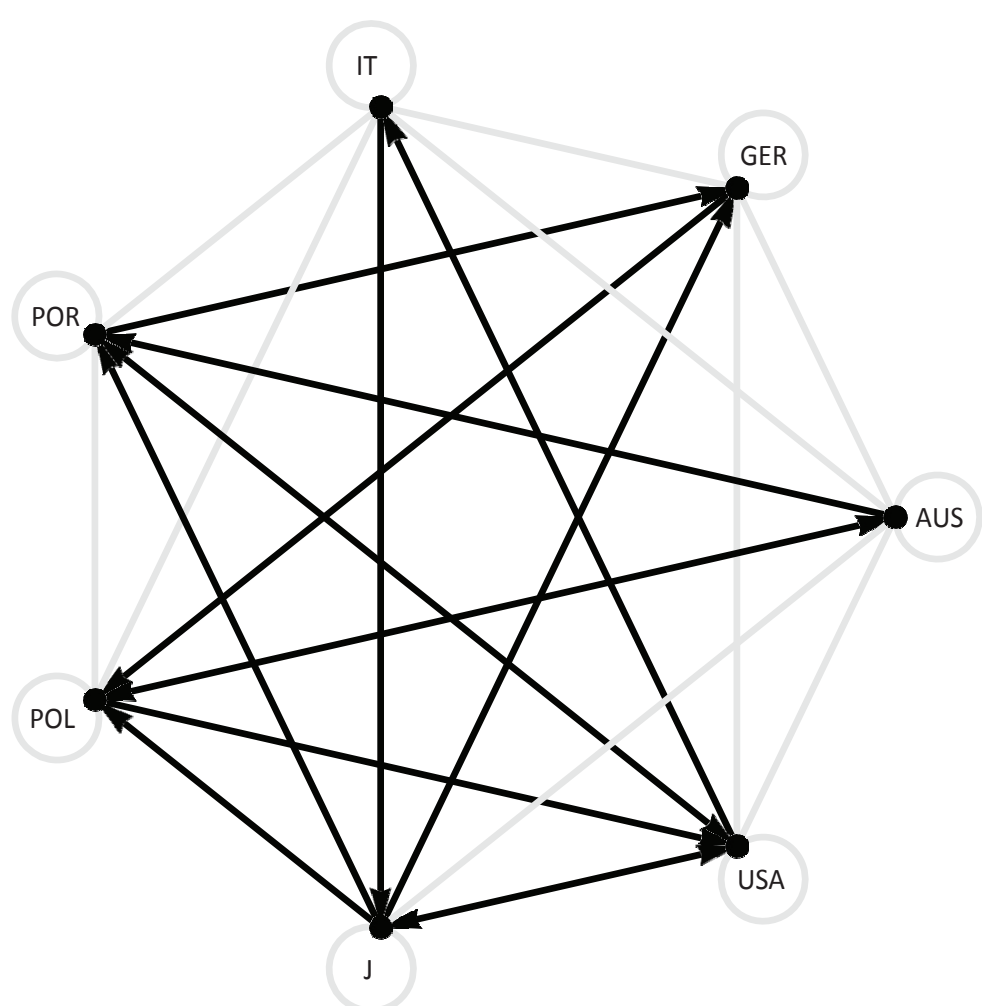

S o u r c e : own calculations.

\section{REFERENCES}

Antonakakis, N., \& Vergos, K. (2013). Sovereign Bond Yield Spillovers in the Euro Zone during the Financial and Debt Crisis. Journal of International Financial Markets. Institutions and Money, 26, 258-272. http://dx.doi.org/10.1016/j.intfin.2013.06.004.

Arghyrou, M.G., \& Kontonikas, A. (2012). The EMU Sovereign-Debt Crisis: Fundamentals, Expectations and Contagion. Journal of International Financial Markets. Institutions and Money, 22(4), 658-677. http://dx.doi.org/10.1016/j.intfin.2012.03.003.

Balli, F. (2009). Spillover Effects on Government Bond Yields in Euro Zone. Does Full Financial Integration Exists in European Government Bond Markets? Journal of Economics and Finance, 33(4), 331-363. http://dx.doi.org/10.1007/s12197-008-9029-3.

Beirne, J., \& Fratzscher, M. (2013). The Pricing of Sovereign Risk and Contagion during the European Sovereign Debt Crisis. Journal of International Money and Finance, 34, 60-82. http://dx.doi.org/10.1016/j.jimonfin.2012.11.004. 
Bradley, B., \& Taqqu, M. (2004). Framework for Analyzing Spatial Contagion between Financial Markets. Finance Letters, 2(6), 8-15.

Durante, F., \& Foscolo, E. (2013). An Analysis of the Dependence Among Financial Markets by Spatial Contagion. International Journal of Intelligent Systems, 28(4), 319-331. http://dx.doi.org/10.1002/int.21578.

Durante, F., Foscolo, E., \& Weissensteiner, A. (2017). Dependence between Stock Returns of Italian Banks and the Sovereign Risk. Econometrics 2017, 5(23), 1-14. http:// dx.doi.org/10.2139/ssrn.2124934.

Durante, F., \& Jaworski, P. (2010). Spatial Contagion between Financial Markets: A Copula-Based Approach. Applied Stochastic Models in Business and Industry, 26(5), 551-564. http://dx.doi.org/10.1002/asmb.799.

Durante, F., \& Sempi, C. (2010). Copula Theory: An Introduction. In P. Jaworski, F. Durante, W. Haerdle, T. Rychlik (Eds.). Copula Theory and Its Applications. Lecture Notes in Statistics. New York: Springer.

Durante, F., Foscolo, E., Jaworski, P., \& Wang, H. (2014). A Spatial Contagion Measure for Financial Time Series. Expert Systems with Applications, 41(8), 4023-4034. http:// dx.doi.org/10.1016/j.eswa.2013.12.020.

Durante, F., Foscolo, E., Jaworski, P., \& Wang, H. (2015). Connectedness Measures of Spatial Contagion in the Banking and Insurance Sector. In P. Grzegorzewski, M. Gagolewski, 0. Hryniewicz, M.A. Gil (Eds.). Strengthening Links Between Data Analysis and Soft Computing Advances in Intelligent Systems and Computing. New York: Springer, 217-232. http://dx.doi.org/10.1007/978-3-319-10765-3.

Ehrmann, M., Fratzscher, M., \& Rigobon, R. (2005). Stock, Bonds, Money Markets and Exchange Rates: Measuring International Financial Transmission, working paper, http://www.nber.org/papers/w11166.pdf (accessed: 18.04.2018).

Embrechts, P. (2009). Copulas: A Personal View. Journal of Risk and Insurance, 76(3), 639-650. http://dx.doi.org/10.1111/j.1539-6975.2009.01310.x.

Jaworski, P., \& Pitera, M. (2014). On Spatial Contagion and Multivariate GARCH Models. Applied Stochastic Models in Business and Industry, 30(3), 303-327. http://dx.doi. org/10.1002/asmb.1977.

Joe, H. (2014). Dependence Modeling with Copulas. Boca Raton: CRC Press.

Kemp, M. (2011). Extreme Events: Robust Portfolio Construction in the Presence of Fat Tails. Chichester: Wiley Finance. http://dx.doi.org/10.1002/9781119207030.ch3.

Mazier, J., \& Petit, P. (2013). In Search of Sustainable Paths for the Eurozone in the Troubled Post-2008 World. Cambridge Journal of Economics, 37, 513-532. http://dx.doi. org/10.1093/cje/bet012.

Mink, M., \& de Haan, J. (2013). Contagion during the Greek Sovereign Debt Crisis. Journal of International Money and Finance, 34, 102-113. http://dx.doi.org/10.1016/j.jimonfin.2012.11.006.

Muellbauer, J. (2013). Conditional Eurobonds and the Eurozone Sovereign Debt Crisis. Oxford Review of Economic Policy, 29(3), 610-645. http://dx.doi.org/10.1093/oxrep/ grt032.

Nelsen, R.B. (2006). An Introduction to Copulas. New York: Springer. http://dx.doi. org/10.1007/978-1-4757-3076-0. 
Sklar, A. (1959). Fonctions de Répartition à n Dimensions et Leurs Marges. Publications de l'Institut de Statistique de l'Université de Paris, 8, 229-231.

World Bank (2016). Definitions of Contagion, http://econ.worldbank.org/WBSITE/ EXTERNAL/EXTDEC/EXTRESEARCH/EXTPROGRAMS/EXTMACROECO/0,,conten tMDK:20889756 pagePK:64168182 piPK:64168060 theSitePK:477872,00.html (accessed: 1.09.2016).

Yunus, N. (2013). Contagion in International Financial Markets: A Recursive Cointegration Approach. Journal of Multinational Financial Management, 23(4), 327-337. http://dx.doi.org/10.1016/j.mulfin.2013.06. 